\title{
Hepatitis E in pregnancy: A case report
}

\author{
Ravi A. Zala ${ }^{1, *}$, Vishal M. Sharma ${ }^{2}$, Bhavesh B. Airao ${ }^{3}$, Manish R. Pandya ${ }^{4}$ \\ ${ }^{1}$ Senior Resident, ${ }^{2}$ Junior Resident, ${ }^{3}$ Associate Professor, ${ }^{4}$ Professor \& HOD, Dept. of Obstetrics and Gynecology, Scientific \\ Research Institute.....
}

*Corresponding Author:

Email: drravizala2503@gmail.com

\begin{abstract}
Viral hepatitis is most common infectious disease in developing countries. Hepatitis E in particular has wide geographical distribution variation and either occur as epidemic or seen as sporadic cases. When pregnant woman affected with hepatitis E, disease will be more severe. If the woman is in second or third trimester where chance of fulminant failure is more with high mortality rate. Here, we are presenting a case of viral hepatitis complicating pregnancy, where women goes into spontaneous preterm labour, complicating in hepatic encephalopathy. Due to proper intervention further harm was prevented.
\end{abstract}

Keywords: Viral hepatitis, Hepatitis E, Fulminant hepatic failure, Pregnancy.

\section{Introduction}

In India hepatitis is a major health problem. Despite of improving sanitation, health awareness, socio economic condition. Both maternal and fetal morbidity and mortality highly increased when a pregnant woman affected with hepatitis E. hepatitis $\mathrm{E}$ is most common hepatitis in adults, $1 / 3^{\text {rd }}$ of the global population appears to have been

Affected. ${ }^{1,9}$

Hepatitis is a inflammation of a liver, which can be self limiting or can progress into fibrosis, cirrhosis or liver neoplasm. Most common cause of hepatitis in the world is hepatitis viruses. Although other infections, toxic substances such as alcohol, certain drugs and autoimmune diseases also can cause hepatits.

There are mainly five types of hepatits virus: A, B, C, D and E. recently hepatitis $G$ was invented. Type B \& $\mathrm{C}$ lead to chronic disease in millions of people and together are the most common cause of liver cirrhosis and neoplasm.

Hepatitis A and $\mathrm{E}$ are typically caused by ingestion of contaminated food \& water. Hepatitis B, C and D usually caused by parental route with infected body fluid such as blood. Commonest mode of transmission of these agents is by contact with infected blood or blood products, medical procedures which are invasive and with usage of infected equipments. Hepatitis B infection has also vertical transmission and it can also spread by sexual contacts.

Hepatitis G virus is also known as GBV-C. It is a single stranded RNA and classified as flaviviridae. It is a rare cause of hepatic inflammation, although viremia and chronic infection is also seen. Level of serum aminotransferase is normal. HGV shares $27 \%$ of homology with HCV. Most of the time patient is asymptomatic. HGV can cause chronic inflammation and viremia. However there is no strong evidence saying that HGV can cause fulminant hepatitis or chronic liver disease. It also seen that concurrent infection with hepatitis B or C has no effect on severity of disease. Acute infection with $\mathrm{HGV}$ is generally associated with no symptoms or sometimes jaundice, hematuria, fatigue, nausea, vomiting and abdominal pain is seen.

\section{Case Report}

A 22 yr. old primigravida with 24 week of gestation was coming to casualty department with complain of yellowish discolorations of sclera, irrelevant talking and behavior since 5 hour. On admission general examination she was deeply icteric and conscious but not oriented to time, place and person. Her pulse was $94 / \mathrm{min}$ and BP $114 / 70 \mathrm{~mm} \mathrm{hg}$. Uterus correspond to week of gestation with cephalic presentation and fetal heart rate was $146 / \mathrm{min}$. Her $\mathrm{Hb}$ was $10.5 \mathrm{gm} / \mathrm{dl}$, TLC $32,400 /$ cumm, and platelet count was 3, 50,000/cumm. On peripheral smear microcytic hypochromic RBCs with few eliptocytes and neutrophilic leukocytosis. Biochemical parameter was following: Total bilirubin: $15.13 \mathrm{mg} / \mathrm{dl}$, direct $9.96 \mathrm{mg} / \mathrm{dl}$, and indirect $5.17 \mathrm{mg} / \mathrm{dl}$. Total protein: $6.1 \mathrm{gm} / \mathrm{dl}$, albumin $2.6 \mathrm{gm} / \mathrm{dl}$, globulin $3.5 \mathrm{gm} / \mathrm{dl}, \mathrm{A}: \mathrm{G}$ ratio $=1: 1.35 \mathrm{SGPT} 831$ unit/lit(normal range $=14-59$ unit/lit), SGOT 471.8 unit/lit(normal range $=<31$ unit/lit), Serum ammonia 276.05 microgram/dl(normal range $=\quad 27-90$ microgram/dl),Serum ALP 142.47IU/lit( normal range= 28-78 IU/lit), LDH 499.9(normal range= up to 245IU/lit), INR 4.19 ( normal range upto2). Serological test for anti IgM HEV was positive and final diagnosis hepatitis E was made. Her INR ratio after 4 day was 1.62. Meanwhile, she goes into spontaneous labour on third day of admission. And delivered $1 \mathrm{~kg}$ female child which was died soon after birth as relative refused for admission in NICU for further management of baby. Placenta and membrane delivered spontaneously and uterus was well contracted. Active management of third stage of labour was done as baby was delivered. No active bleeding was found. Labour was uneventful. As pt. and her relatives refused to do investigation on still 
born baby. We doesn't know the cause of pre term labour and whether baby is HEV reactive or not. Pt.'s Plate6let count was decrease to $90000 /$ cumm on day 5 of admission, which was corrected by blood products. Further management done with higher antibiotics (inj. Meropenem 1G IV TDS given for 10 days, Inj. Vancomycin 500 IV BD given for 5 days, inj. Cefotaxime iv TDS for 5 days, tab. Levofloxacin750mg BD given for 5 days, tab. Metronidazole 400mg TDS given for 5 days), blood products (3 unit PCV, 10 unit FFP, 3 unit Whole blood) \& further supportive measures done with inj. Human albumin $(100 \mathrm{ml})$ pint, inj. Vit. K, tab. Urodeoxycholic acid 300mg BD, Syp. Lactulose 2tsf TDS, tab.alpha lipoic acid (200mg) +N-acetyl cysteine (200mg) +selenomethionine (100mg) +silymarin (210mg) BD, tab.Multivitamin BD. She was discharged on her postpartum day 20. And serum total bilirubin $=6.78$, direct $=6.27$ indirect $=0.51$. INR $=1.5 \mathrm{Hb}$ $11.6 \mathrm{gm} / \mathrm{dl}$, TLC $=6,900 / \mathrm{cumm}$, platelet count: $2,23,000 /$ cumm on peripheral smear normocytic normochromic RBC. Patient advised to consume fat free diet on discharge.

Table 1: Haematological parameter of the patient

\begin{tabular}{|l|c|c|c|}
\hline \multicolumn{1}{|c|}{ Date } & Hb & TLC & PC \\
\hline $2 / 6 / 17$ & 10.5 & 32400 & $3,50,000$ \\
\hline $3 / 6 / 17$ & 9.6 & 15,300 & $3,23,000$ \\
\hline $4 / 6 / 17$ & 5.9 & 27,200 & $3,20,000$ \\
\hline $5 / 6 / 17$ & 7.2 & 16,100 & 90,000 \\
\hline $6 / 6 / 17$ & 6.0 & 5,200 & $1,28,000$ \\
\hline $7 / 6 / 17$ & 6.7 & 9,800 & $1,34,000$ \\
\hline $8 / 6 / 17$ & 9.3 & 11,800 & $1,40,000$ \\
\hline $9 / 6 / 17$ & 10.2 & 12,800 & $1,32,000$ \\
\hline $10 / 6 / 17$ & 10.9 & 12,600 & $1,50,000$ \\
\hline $11 / 6 / 17$ & 10.7 & 10,800 & $1,45,000$ \\
\hline $12 / 6 / 17$ & 10.3 & 9,000 & $1,20,000$ \\
\hline $19 / 6 / 17$ & 8.9 & 6,400 & $2,09,000$ \\
\hline $23 / 6 / 17$ & 11.6 & 6,900 & $2,23,000$ \\
\hline
\end{tabular}

\section{Discussion}

\section{Hepatitis $\mathbf{E}$ is inflammatory liver disease caused by HEV}

HEV is a single stranded, non-enveloped RNA virus and is the only virus in the genus hepevirus. And family hepeviridae. It was first reported in India in $1970 .^{2}$ Most of the HEV infections have a silent clinical course but in symptomatic cases incubation period can range from 1460days with mean 5-6weeks. Initial prodromal symptoms of acute viral hepatitis are systemic \& quite variable constitutional symptoms of anorexia, nausea \&vomiting, fatigue, malaise, arthralgia, myalgia, headache, photophobia, pharyngitis, cough\& coryza may proceed onset of jaundice by 1-2 week. With onset of jaundice, the constitutional prodromal symptoms usually diminish. Liver enlargement \& abnormalities in liver biochemical tests are still evident. ${ }^{2}$ Every year, there are an estimated 20 million HEV infections worldwide, leading to an estimated 3.3 million symptomatic cases of hepatitis E, and 56600 hepatitis Erelated deaths. WHO estimates that hepatitis E caused approximately 44000 deaths in 2015 (accounting for $3.3 \%$ of the mortality due to viral hepatitis). The virus is transmitted via the faecal-oral route, principally via contaminated water. Hepatitis $\mathrm{E}$ is found worldwide, but the prevalence is highest in East and South Asia. ${ }^{10}$

\section{Hepatitis $\mathbf{E}$ infection and pregnancy}

The water borne RNA virus usually enterically transmitted by contaminated water supply. Hepatitis E is probably most common cause of hepatitis. Pregnant woman have a higher case fatality than a non-pregnant woman. Higher hepatitis E viral load and increased cytokine secretion in pregnant woman may be the factor in the development of fulminant hepatitis. Mortality rate among pregnant woman ranges between 5-25\% . Particularly infected in third trimester which is higher than men and non-pregnant woman. ${ }^{3}$ It has been reported that a significant proportion of pregnant woman with acute hepatitis E progress to acute liver failure with short pre encephalopathy period with rapid development of cerebral edema and high occurrence of DIC. ${ }^{4}$ Hepatitis E in pregnancy is also associated with higher rates of spontaneous abortions, IUD and preterm labour. ${ }^{3}$

\section{HEV Genotypes}

There are four genotypes of HEV found to have unique geographic distribution.

Genotype1 includes Asian and African HEV strains and genotype 2 include Mexican HEV strain. Genotype 3 is most common in china. ${ }^{5,6}$ Genotype 4 include human and swine HEV strain from Asia. Genotype 1 and 2 appear to be more virulent than genotype 3 and $4 .^{7}$ Diagnostic method broadly classify into direct and indirect. Direct method detects viral protein or nucleic acid in blood and stool sample whereas indirect method 
detects anti HEV IgM and IgG antibodies in the given sample. Anti HEV IgM is detectable four days after onset of jaundice and persists up to 3 to 5 months. IgG antibodies develop and peak at about 4 week after onset of symptom and persist for a variable period 1 to 14 year of infection.

\section{Management}

Prevention: Management includes preventive measures includes clean drinking water, good sanitation, and personal hygiene. In endemic areas one should avoid drinking water and eating uncooked food. Boiling of the water may prevent infection.

Hepatitis E is preventable by vaccination. Studies conducted in Nepal and China have shown 95\% of vaccine efficacy in preventing genotype $1 \mathrm{HEV}$ infection and clinical course. ${ }^{12,13}$ vaccine not only prevent the genotype $1 \mathrm{HEV}$ infection but genotype 4 was also prevented with the vaccine. That indicates cross protection against different HEV genotypes. Vaccine efficacy against genotype 3 is not known. China had approved vaccine against genotype $1 \mathrm{HEV}$ in December 2011. A study proved long term efficacy of the vaccine as it induces sustained level of antibodies and provides protection against $\mathrm{HEV}$ for up to 4.5 years.

Efficacy of the vaccines are needed to be evaluate for their duration of pretection in special groups like patients with end stage liver disease or immunocompromised individuals.

\section{Treatment of acute $\mathrm{HEV}$ infection}

In an immunocompetent individual acute hepatitis E infection usually requires only symptomatic treatment, as they are able to clear virus spontaneously. A study showed rapid improvement of liver enzyme and function after giving ribavirin for 21 days in patient with severe acute hepatitis E. ${ }^{12}$ Although ribavirin is contraindicated in pregnancy because of its teratogenicity. Risk of untreated HEV to the mother \& fetus are high. ${ }^{13}$ Risk benefit ratio should be consider.

\section{Treatment of chronic HEV infection}

It is desirable to clear the viruses from transplant recipient with chronic hepatitis E. The first of all immunosuppressive therapy should be reduced, as reduction in imuunosuppression leads to $30 \%$ of viral clearance. Calcineurin inhibitor such as cyclosporine A, tacrolimus and mTOR inhibitor such as rapamycin, everolimus showed in vitro effect on stimulation of HEV repliocation. ${ }^{14}$ There is no role of steroid in HEV replication in vitro. ${ }^{15}$

In a patient you can't reduce the immunosuppressive therapy and those who do not achieve viral clearance after immunosuppressive therapy, antiviral therapy should be started. Ribavirin in a dose of 600-1000mg /day is given for 3 month is the first line treatment for the patient with chronic hepatitis $\mathrm{E}$ who are not able to clear virus after immunosuppression is reduced. ${ }^{16}$ G1634 mutation in the RdRp domain of HEV ORF1 protein is responsible for resistance against ribavirin. In this condition peglycated interferon alfa is used. It is seen that ribavirin causes HEV mutagenesis and produces distinct mutants in a person who is on ribavirin therapy.

Patient with liver transplantation, if peglycated interferon alfa is gives then after 3-12 month there is a mark decrease in of HEV viral load from circulation. ${ }^{18}$ However treatment with interferon lead to significant adverse effect like organ rejection is seen with heart and kidney transplant individuals. A newer drug sofosbuvir, a nucleotide analogue, inhibits RNA replication in HEV genotype 3 . If this drug used in a combination with ribavirin an additive antiviral effect is seen. ${ }^{19}$

\section{Conclusion}

Acute hepatitis E in pregnancy has high mortality and morbidity for both mother and fetus. Each patient can present differently clinically. All measure to be kept ready to handle the condition. Special concerns are given to the pregnant women with hepatitis $\mathrm{E}$ infection.

\section{References}

1. Kasper, Fauci, Hauser, Longo, Jameson, Loscalzo. Harrison's principles of internal medicine $19^{\text {th }}$ edition, 2010-11. Kasper, Fauci, Hauser, Longo, Jameson, Loscalzo. Harrison's principles of internal medicine $19^{\text {th }}$ edition, 2015-16.

2. Khuroo MS, Teli MR, Skidmore S, Sofi MA, Khuroo MI. Incidence and severity of viral hepatitis in pregnancy. Am J Med. 1981; 70(2):252-5.

3. Khuroo MS, Kamili S. Aetiology, clinical course and outcome of sporadic acute viral hepatitis in pregnancy. $\mathrm{J}$ Viral Hepat. 2003;10:61-9.

4. Zhu G, Qu Y, Jin N, Sun Z, Liu T, Lee H, et al. Seroepidemiology and molecular characterization of hepatitis E virus in Jilin, China. Infection. 2008; 36(2):140-6.

5. Ijaz S, Arnold E, Banks M, Bendall RP, Cramp ME, Cunningham R, et al. Non-travel-associated hepatitis $\mathrm{E}$ in England and Wales: demographic, clinical, and molecular epidemiological characteristics. J Infect Dis. 2005;192(7):1166-72.

6. Purcell RH, Emerson SU. Hepatitis E: an emerging awareness of an old disease. J Hepatol. 2008; 48(3):494503 .

7. Ahmed A, Ali IA, Ghazal H, Fazili J, Nusrat S. Mystery of hepatitis E virus: recent advances in its diagnosis and management. Int J Hepatol. 2015;2015:872431.

8. Mall ML, Rai RR, Phillip M. Seroepidemiology of hepatitis $\mathrm{A}$ in India: changing pattern. Ind $\mathrm{J}$ Gastroenterol. 2001;20(4):130-2.

9. http://www.who.int/mediacentre/factsheets/fs280/en/

10. Barnaud E, Rogee S, Garry P, Rose N, Pavio N. Thermal inactivation of infectious hepatitis $\mathrm{E}$ virus in experimentally contaminated food. Appl Environ Microbiol. 2012 Aug. 78(15):5153-9.

11. Shrestha MP, Scott RM, Joshi DM, et al. Safety and efficacy of a recombinant hepatitis E vaccine. $N$ Engl J Med. 2007 Mar 1. 356(9):895-903.

12. Zhu FC, Zhang J, Zhang XF, et al. Efficacy and safety of a recombinant hepatitis $E$ vaccine in healthy adults: a largescale, randomised, double-blind placebo-controlled, phase 3 trial. Lancet. 2010 Sep 11. 376(9744):895-902. 
13. .Kamar N, Abravanel F, Selves J, et al. Influence of immunosuppressive therapy on the natural history of genotype 3 hepatitis-E virus infection after organ transplantation. Transplantation. 2010 Feb 15. 89(3):35360.

14. Kamar N, Lhomme S, Abravanel F, et al. An early viral response predicts the virological response to ribavirin in hepatitis $\mathrm{E}$ virus organ transplant patients. Transplantation. 2015 Oct. 99(10):2124-31.

15. Lhomme S, Kamar N, Nicot F, et al. Mutation in the hepatitis $\mathrm{E}$ virus polymerase and outcome of ribavirin therapy. Antimicrob Agents Chemother. 2015 Dec 28. 60(3): 1608.

16. Todt D, Gisa A, Radonic A, et al. In vivo evidence for ribavirin-induced mutagenesis of the hepatitis E virus genome. Gut. 2016 Oct. 65 (10):1733-43.

17. Kamar N, Rostaing L, Abravanel F, et al. Pegylated interferon-alpha for treating chronic hepatitis E virus infection after liver transplantation. Clin Infect Dis. 2010 Mar 1. 50(5):e30-3.

18. Debing Y, Moradpour D, Neyts J, Gouttenoire J. Update on hepatitis E virology: Implications for clinical practice. J Hepatol. 2016 Jul. 65(1):200-12. 